Research Article

\title{
Effectiveness of Physical Activity and Finger Millet-Based Food Supplement on Biochemical Parameters and Bone Mineral Density among Premenopausal Women
}

\author{
Golda Sahaya Rani ${ }^{D},{ }^{1}$ Aruna Swaminathan, ${ }^{2}$ and Rajagopalan Vijayaraghavan ${ }^{3}$ \\ ${ }^{1}$ Sri Sathya Sai College of Nursing, Chengalpet 603108, India \\ ${ }^{2}$ Department of Nursing, Jazan University, Jazan, Saudi Arabia \\ ${ }^{3}$ Department of Research and Development, Saveetha Institute of Medical and Technical Sciences, Chennai 602105, India
}

Correspondence should be addressed to Golda Sahaya Rani; goldarani@gmail.com

Received 16 June 2021; Revised 7 October 2021; Accepted 9 October 2021; Published 18 October 2021

Academic Editor: Talha Bin Emran

Copyright (c) 2021 Golda Sahaya Rani et al. This is an open access article distributed under the Creative Commons Attribution License, which permits unrestricted use, distribution, and reproduction in any medium, provided the original work is properly cited.

\begin{abstract}
The effectiveness of physical activity and finger millet-based food supplement on biochemical parameters and bone mineral density (BMD) among premenopausal women were studied. Serum calcium, phosphorus, alkaline phosphatase, and BMD of 720 women (30-40 years) were analyzed. From them, 150 women with low BMD ( $t$-score, -1 to -2.5$)$ and low calcium $(<9.0 \mathrm{mg} / \mathrm{dL})$ were randomized to control and experimental groups, equally. The experimental group was given 5 days per week physical activity, for 3 months, and a diet supplement of finger millet-based sweet balls (ragi laddu), 3 days per week for 3 months. The above parameters were measured as the posttest. Physical activity was assessed by the General Practice Physical Activity Questionnaire. A $24 \mathrm{~h}$ recall assessment was carried out for the diet supplement, and self-reported activity checklist was maintained for physical activity. Among 720 women, $163(22.6 \%)$ showed BMD, $t$-score $<-1.0$, and calcium $<9.0 \mathrm{mg} / \mathrm{dL}$ $(p<0.001)$. The serum phosphorus and alkaline phosphatase were also low $(p<0.001)$. After the supplementation to the experimental group, all the biochemical parameters, BMD, and physical activity score showed significant improvement in the posttest $(p<0.001)$. This study showed significantly low BMD and calcium among premenopausal women. Physical activity and finger millet supplement improved the calcium level and BMD.
\end{abstract}

\section{Introduction}

Osteoporosis is a global public health problem leading to increased bone fracture [1]. A study in Indian women showed $36 \%$ with osteopenia and $4 \%$ with osteoporosis. Low bone mineral density (BMD) was reported with the advancement of age and the menopausal status [2]. The high incidence of low bone density in women is due to decreased estrogen production during menopause [3]. There is calcium deficiency and a reduction in BMD. Women should have routine bone test and effective care to prevent complications [4]. Fractures caused by osteoporosis are important public health concern. Low BMD is common in women over the age of 40 and particularly after menopause [5].
To prevent osteopenia and osteoporosis, calcium and vitamin D supplements are required. Food containing high calcium, potassium, magnesium with vitamins and other minerals, viz., phosphorus, iron, and zinc are preferable for the normal bone metabolism to control osteopenia and osteoporosis [6]. Nutrition is an essential factor in maintaining the bone mass, particularly vegetable consumption [7]. Several millet grains also have a very high nutritive value, and among them, finger millet (Eleusine coracana, ragi in Hindi) is rich in calcium, protein, and essential amino acids [8]. Finger millet grain is popular in Asian and African countries due to the health benefits $[9,10]$. Finger millet is considered as a super cereal in the United States. In more than 25 countries across Africa and Asia, finger millet is used accounting for $12 \%$ of the total millet consumption. Finger 
millet is used in cakes, pudding, and porridge [11]. Finger millet provides amino acid methionine, which is deficient in other starch cereals. Millets are gluten-free and processed as millet flour for use. It is a rich source of phosphorus, iron, magnesium, calcium, and fiber [12]. Finger millet has 5-30 times more calcium than other grains [13].

Physical activity is essential for bone gain, and activities such as weight-bearing activities and muscle strengthening are recommended for a healthy bone [14, 15]. Physical activity has been shown to improve balance, bone growth, range of motion, and preserve bone mass. Regular physical activity in the early life strengthens the hip and prevents osteoporosis [16, 17]. Hence, it is important to create awareness to prevent bone deterioration from the premenopausal period [18].

Healthcare professionals should be aware of bone loss in various disease conditions and should prevent it with proper intervention supported by clinical biomarkers [19]. Osteoporosis prevention initiatives for premenopausal women are required for bone health and avoid bone loss. Several methods are available to prevent bone loss. In the present study, the effectiveness of physical activity and finger milletbased food supplement was evaluated on biochemical parameters and BMD among premenopausal women.

\section{Materials and Methods}

2.1. Participants. 720 women of premenopausal age (30-40 years), members of a private women's organization (Kanchi Women's Sangamam Mutual's, Tamil Nadu, India), were initially screened for BMD and biochemical parameters. Among them, 150 women with BMD, $t$-score of -1 to -2.5 , and serum calcium $<9.0 \mathrm{mg} / \mathrm{dL}$ were included in this study. They were divided into control and experimental groups, equally by a random number table. Women with mental health problem and other systemic disease were excluded from the study. This study was approved by Institutional Ethics Committee of Saveetha Medical College and Hospital, Chennai (SMCH-IEC/006/04/2019), and carried out between May 2019 to April 2020. An information sheet was provided in English and local language (Tamil) to each participant, and signed consent to participate in the study was obtained.

2.2. Methodology. Serum calcium (Ca), phosphorus (P), and alkaline phosphatase (ALP) were analyzed by an autoanalyzer as per manufacture's procedure (Microlab 300, ELITechGroup, France), and BMD was measured by an ultrasound bone densitometer (CM-200, Furuno Electric Co., Ltd., Japan) for all the 720 women. The 557 premenopausal women who did not meet the criteria (BMD, $t$-score of -1 to -2.5 and serum calcium $<9.0 \mathrm{mg} /$ $\mathrm{dL}$ ) were excluded, and 13 women who did not volunteer to the osteoporosis prevention program due to personal reasons were also excluded. The 150 women who gave the signed consent for the intervention study were allocated randomly to the control and experimental groups. Pretest information on demographic profile by the questionnaire was recorded. The osteoporosis prevention program for the experimental group consisted of general awareness, physical activity, and diet supplementation. Structured education was provided once, on osteoporosis prevention (flash cards for $20 \mathrm{~min}$ ). The physical activity consisted of spine (resistance), hip (strengthening), shoulder (resistance), and knee (strengthening). Pamphlets were given to the experimental group women after demonstration and was instructed to continue for 5 days a week for 3 months. Ragi laddu (finger millet sweet ball) supplement was given to the experimental group, three days per week for 3 months. The laddu was prepared using ragi flour $(800 \mathrm{~g})$, powdered jaggery $(400 \mathrm{~g})$, and ghee $(300 \mathrm{~g}) .100 \mathrm{~g}$ of ghee was heated in a frying pan and ragi was roasted for 5 min in low flame. Powdered jaggery was added slowly and remaining ghee was poured, and mixed thoroughly. After cooling, the mixture was divided into 10 equal parts and made into laddu (150 g). All hygienic precautions were adhered in the preparation of the laddu by one of the investigators. The laddu was prepared every week fresh and 3 pieces were distributed to each experimental group women during the weekly meeting. A $24 \mathrm{~h}$ recall assessment was carried out for the diet supplement, and self-reported activity check list was maintained physical activity. The prepared laddu was certified by an approved food testing laboratory (Chennai Testing Laboratory Pvt. Ltd., India). At the end of the experimentation, analysis of serum calcium, phosphorus, and alkaline phosphatase and $\mathrm{BMD}$ were carried out for both control and experimental groups as the posttest.

The physical activity was assessed by the General Practice Physical Activity Questionnaire (GPPAQ). For the assessment of physical activity, the General Practice of Physical Activity Questionnaire (GPPAQ) can be used which consists of seven self-explanatory questions and can be answered within one minute. The GPPAQ is a selfassessment physical activity questionnaire and is commonly used in primary care. The GPPAQ includes type of physical activity, duration, and walking speed and is designed for adults. A physical activity index can be computed and categorized as active, moderately active, moderately inactive, and inactive. [20, 21]. The levels of serum calcium, phosphorous, and alkaline phosphatase (ALP) were measured as biochemical indicators of bone turnover. ALP is a well-known marker for bone disorders [22].

2.3. Statistical Analysis. The data were analyzed by the $\chi^{2}$ test, Mann-Whitney rank sum test, Wilcoxon signed rank test, one-way ANOVA, and two-way repeated measures ANOVA with Bonferroni $t$-test for comparison of the variables. Linear regression was used for correlating the variables. Since the physical activity was assessed with a questionnaire, nonparametric statistics was used. For the biochemical and BMD measurements, parametric statistics was used assuming normal distribution. SigmaPlot 13 (Systat software, USA) was used for the statistical analysis and for plotting the graphs. 
TABLE 1: Classification of bone mineral density (BMD; $t$-score) and serum calcium (Ca, $\mathrm{mg} / \mathrm{dL}$ ) with serum phosphorus (P, mg/dL), alkaline phosphatase (ALP, U/L), and age (years) of premenopausal women.

\begin{tabular}{|c|c|c|c|c|c|c|c|}
\hline S. No. & Category & $\mathrm{BMD}$ & $\mathrm{Ca}$ & Number & $\mathrm{P}$ & ALP & Age \\
\hline \multirow{2}{*}{1} & \multirow{2}{*}{ Normal } & \multirow{2}{*}{$>-1$} & $<9.0$ & 209 & $3.48 \pm 0.57$ & $82.5 \pm 25.7$ & $35.1 \pm 3.1$ \\
\hline & & & $>9.0$ & 336 & $3.48 \pm 0.61$ & $81.5 \pm 26.3$ & $34.8 \pm 3.2$ \\
\hline \multirow{2}{*}{2} & \multirow{2}{*}{ Osteopenia } & \multirow{2}{*}{-1 to -2.5} & $<9.0$ & 153 & $1.97 \pm 0.48^{*}$ & $33.4 \pm 15.1^{*}$ & $34.8 \pm 3.2$ \\
\hline & & & $>9.0$ & 12 & $3.19 \pm 0.55$ & $87.3 \pm 29.3$ & $34.8 \pm 3.1$ \\
\hline \multirow{3}{*}{3} & \multirow{2}{*}{ Osteoporosis } & \multirow{2}{*}{$<-2.5$} & $<9.0$ & 10 & $1.82 \pm 0.16$ & $30.0 \pm 1.8$ & $33.7 \pm 3.2$ \\
\hline & & & $>9.0$ & 0 & - & - & - \\
\hline & \multicolumn{2}{|c|}{ Statistical analysis } & & $\begin{array}{l}\chi^{2}=122.2 \\
P<0.001\end{array}$ & $\begin{array}{l}F=226.0 \\
P<0.001\end{array}$ & $\begin{array}{l}F=130.0 \\
P<0.001\end{array}$ & $\begin{array}{l}F=0.757 \\
P=0.554\end{array}$ \\
\hline
\end{tabular}

Values are mean $\pm \mathrm{SD}(n=720) . \chi^{2}$ analysis for BMD with $\mathrm{Ca}<9.0$ and $>9.0 \mathrm{mg} / \mathrm{dL}$ groups. ${ }^{*}$ Statistically significant from the respective Ca $>9.0(\mathrm{mg} / \mathrm{dL})$ group by one-way ANOVA with the Bonferroni $t$-test.

\section{Results}

Among the 720 women evaluated, 163 (22.6\%) showed BMD less than $-1.0 t$-score with serum calcium less than $9.0 \mathrm{mg} /$ $\mathrm{dL}$ (Table 1). $\chi^{2}$ analysis showed significant association with low BMD and low calcium level $(p<0.001)$. The serum phosphorus and ALP levels were also significantly low $(p<0.001)$, though there was no significant difference in the age $(p=0.554)$.

Analysis of the laddu revealed $4.66 \mathrm{mg}, 370 \mathrm{mg}$, and $133 \mathrm{mg}$ of iron, calcium, and phosphorus, respectively, per $100 \mathrm{~g}$. The protein content and fiber content were $4.0 \mathrm{~g}$ and $3.8 \mathrm{~g}$ per $100 \mathrm{~g}$ of laddu. The calculated energy was $372 \mathrm{kcal} /$ $100 \mathrm{~g}$ of laddu.

The control and experimental groups serum calcium, phosphorus, and ALP levels and BMD are shown in Figure 1. The mean \pm SEM values of serum calcium of the control pretest, control posttest, experimental pretest, and experimental posttest were $6.95 \pm 0.04,6.94 \pm 0.04,7.04 \pm 0.03$, and $8.29 \pm 0.02 \mathrm{mg} / \mathrm{dL}$, respectively. Two-way RM ANOVA showed a significant difference among the groups $(p<0.001)$, pretest and posttest $(p<0.001)$, and the interaction $(p<0.001)$. There was no significant difference in the pretest $(p=0.074)$, but the posttest showed a significant difference $(p<0.001)$ between control and experimental groups. The control pretest and posttest did not show a significant difference $(p=0.446)$, while the experimental pretest and posttest showed a significant increase in the serum calcium level $(p<0.001)$. The mean \pm SEM values of serum phosphorus of the control pretest, control posttest, experimental pretest, and experimental posttest are $1.86 \pm 0.02,1.84 \pm 0.02,1.84 \pm 0.02$, and $2.59 \pm 0.02 \mathrm{mg} / \mathrm{dL}$, respectively. Similar to serum calcium, serum phosphorus also showed a significant increase in experimental posttest only $(p<0.001)$. The ALP level of the control pretest, control posttest, experimental pretest, and experimental posttest was $29.9 \pm 0.24,29.7 \pm 0.23,29.2 \pm 0.26$, and $39.7 \pm 0.30 \mathrm{U} / \mathrm{L}$, respectively. Though the experimental posttest showed an elevated ALP level, it was within the clinical range.

The mean \pm SEM values of BMD of the control pretest, control posttest, experimental pretest, and experimental posttest are $-1.80 \pm 0.03,-1.80 \pm 0.03,-1.73 \pm 0.04$, and $-0.92 \pm 0.04 \mathrm{~g} / \mathrm{cm}^{2}$, respectively. Similar to serum calcium, there was significant improvement in the experimental posttest in BMD. There was no significant difference in the pretest $(p=0.153)$, but the posttest $(p<0.001)$ showed a significant difference between control and experimental groups. The control pretest and posttest did not show a significant difference $(p=0.928)$, while the experimental pretest and posttest showed a significant increase in BMD $(p<0.001)$.

Table 2 provides the effectiveness on physical activity in control and experimental groups, pretest and posttest. The experimental posttest showed significant improvement $(p<0.001)$ in the physical activity (from median of 0 to 3.2) compared to the control group (from median of 0 to 0 ) based on the GPPAQ. Figure 2 shows the correlation of BMD with calcium, phosphorus, and ALP. A positive correlation was obtained among the variables showing the effectiveness of physical activity and the diet supplement in improving the BMD.

\section{Discussion}

Osteoporosis is not generally considered as a serious disease when compared to other communicable and noncommunicable diseases [23]. Nevertheless, osteoporosisrelated fractures are highly associated with morbidity and mortality [24]. If properly diagnosed and preventive measures are adopted, the risk can be reduced to 50\% [25]. Early diagnosis of osteopenia and osteoporosis in premenopausal women is required for a preventive management [26]. Deficiency in serum calcium was associated with osteopenia and osteoporosis [27]. In the present study $24.3 \%$ of premenopausal women showed low BMD and $51.7 \%$ showed low serum calcium. 22.6\% showed low BMD as well as also low calcium in the premenopausal stage.

Physical exercise has been shown to improve flexibility, strength, posture, and balance in women and also improve bone health [28]. Planned physical activity and sufficient intake of calcium are indicated for premenopausal women $[27,29]$. Multicomponent exercise programme for 12 weeks was found to be suitable for improving the physical function and the quality of life for women with osteoporosis [30]. Weight-bearing and resistance exercises are the ideal lifestyle measures for prevention of osteoporosis among 

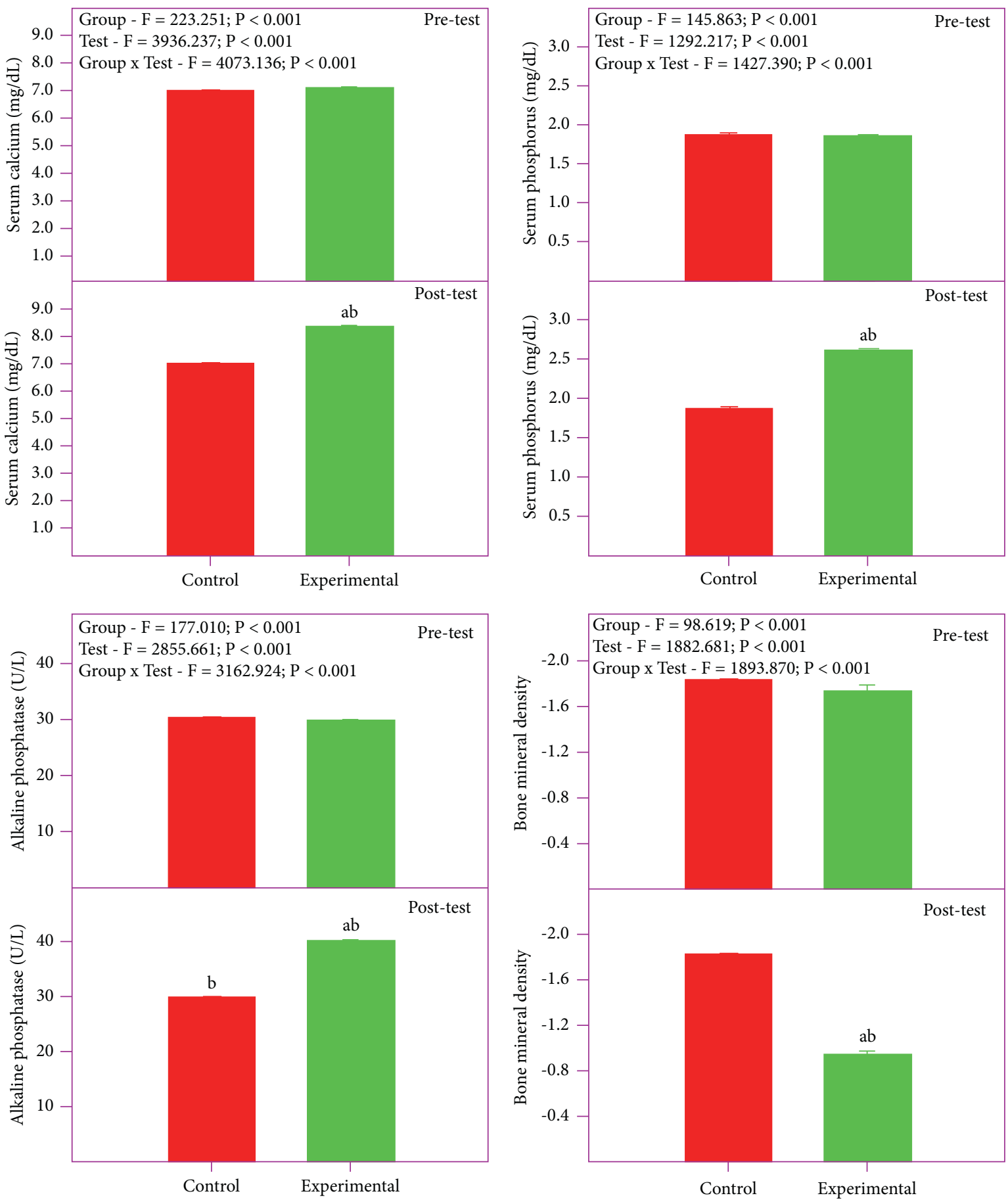

FIGURE 1: Serum calcium, phosphorus, alkaline phosphatase, and bone mineral density in control and experimental groups of premenopausal women. Values are mean $+\mathrm{SE}(n=75$ each). Two-way RM ANOVA with the Bonferroni $t$-test. (a) Significantly different from the respective control group (between group). (b) Significantly different from the respective pretest (within group).

premenopausal women. The physical activity correlated with lowering the fat mass and increased BMD [31].

Several dairy products, vegetables, cereals, millets, and pulses are rich sources of calcium. Diet-based calcium supplement would be more acceptable and easier to practice [32]. Finger millet (ragi, Eleusine coracana) is a rich source of calcium and phosphorus and easily digestible [33]. It has been reported to have several beneficial effects, viz., blood glucose and cholesterol lowering, wound healing, and as a nutritional supplement for children also [34]. Finger millet has antioxidant and antibacterial properties [35]. Jaggery, also known as noncentrifugal sugar, is also rich in minerals and flavonoids [36]. In the present study, serum calcium was increased in the experimental posttest, as a result of the supplementation. Calcium increase is important for the bone metabolism. Dietary supplementation with calcium 
TABLE 2: Physical activity score of control and experimental groups of premenopausal women.

\begin{tabular}{|c|c|c|c|c|c|c|c|}
\hline \multirow{3}{*}{ Groups } & \multirow{3}{*}{ Mean } & \multirow{3}{*}{ Median } & \multirow{3}{*}{ Percentile } & \multicolumn{4}{|c|}{ Statistical analysis } \\
\hline & & & & \multicolumn{2}{|c|}{$\begin{array}{c}\text { Between groups, } \\
\text { Mann-Whitney rank sum } \\
\text { test }\end{array}$} & \multicolumn{2}{|c|}{$\begin{array}{l}\text { Within groups, Wilcoxon } \\
\text { signed rank test }\end{array}$} \\
\hline & & & & $\begin{array}{l}\text { Pretest } \\
\text { Con/exp }\end{array}$ & $\begin{array}{l}\text { Posttest } \\
\text { Con/exp }\end{array}$ & $\begin{array}{c}\text { Con } \\
\text { Pre/post }\end{array}$ & $\begin{array}{c}\text { Exp } \\
\text { Pre/post }\end{array}$ \\
\hline Con-pretest & 0.047 & 0.0 & $0.0-0.0$ & & & & \\
\hline Con-posttest & 0.048 & 0.0 & $0.0-0.0$ & $U=2779$ & $U=0$ & $z=0.447$ & $z=7.550$ \\
\hline Exp-pretest & 0.041 & 0.0 & $0.0-0.0$ & $P=0.781$ & $P<0.001$ & $P=1.0$ & $P<0.001$ \\
\hline Exp-posttest & 3.165 & 3.2 & $3.0-3.4$ & & & & \\
\hline
\end{tabular}

$n=75$ each; Con, control; Exp, experimental.

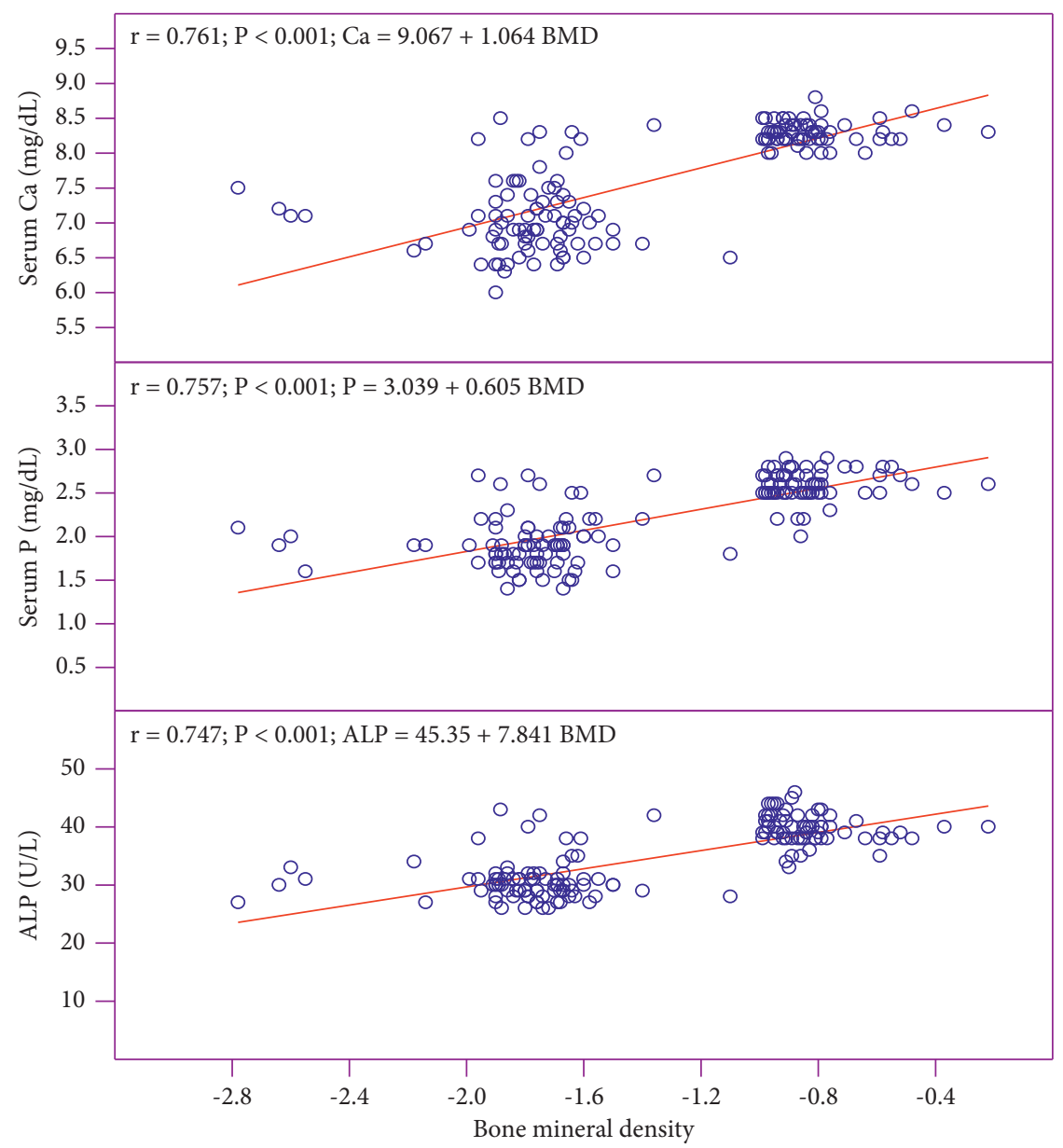

FIGURE 2: Correlation of bone mineral density (BMD) with serum calcium (Ca), phosphorus (P), and alkaline phosphatase (ALP). Combined data of control and experimental posttest $(n=75+75)$.

and vitamins D3 and B6 was found to be effective, improved the BMD, and increased calcium and ALP levels in the high fracture risk group who were undergoing medical rehabilitation [37]. In the present study also, it has been shown that an increase in serum calcium has improved the $t$-score of $\mathrm{BMD}$, and a positive correlation was obtained with serum calcium and BMD $(r=0.761)$. Dairy products fortified with calcium and vitamin $\mathrm{D}$ to postmenopausal women has been shown to significantly influence BMD [38]. The daily requirement of calcium for Indian women is $600 \mathrm{mg}$ [39]. $150 \mathrm{~g}$ of the finger millet laddu supplement would provide more than $500 \mathrm{mg}$ of calcium and that has resulted in increased serum calcium, phosphorus, and BMD in the experimental posttest.

\section{Conclusion}

The present study shows significant low BMD and calcium among premenopausal women. Physical activity and finger millet supplement improved the calcium level 
and BMD. Women in the premenopausal stage should be aware of low BMD and its risk. They should improve their nutrition, particularly calcium from naturally available food products.

\section{Data Availability}

The data are available at the Department of Research and Development, Saveetha Institute of Medical and Technical Sciences, Chennai, India.

\section{Conflicts of Interest}

The authors declare that there are no conflicts of interest.

\section{References}

[1] J. Slomian, G. Appelboom, O. Ethgen, J. Y. Reginster, and O. Bruyère, "Can new information and communication technologies help in the management of osteoporosis," SAGE Women's Health, vol. 10, no. 3, pp. 229-232, 2014.

[2] J. Chawla, N. Sharma, D. Arora, M. Arora, and L. Shukla, "Bone densitometry status and its associated factors in peri and post menopausal females: a cross sectional study from a tertiary care centre in India, Taiwan," Journal of Obstetrics and Gynaecology, vol. 57, no. 1, pp. 100-105, 2018.

[3] S. N. Mann, K. S. Pitel, M. H. Nelson-Holte et al., "17 $\alpha$-Estradiol prevents ovariectomy-mediated obesity and bone loss," Experimental Gerontology, vol. 142, Article ID 111113, 2020.

[4] X. Yu, Y. Zhang, P. Han et al., "Effects of different living conditions on the risk of osteoporosis in Chinese communitydwelling elderly: a 3-year cohort study," Journal of International Medical Research, vol. 48, no. 8, pp. 1-11, 2020.

[5] R. Fabiani, G. Naldini, and M. Chiavarini, "Dietary patterns in relation to low bone mineral density and fracture risk: a systematic review and meta-analysis," Advances in Nutrition, vol. 10, no. 2, pp. 219-236, 2019.

[6] G. A. D. Miggiano and L. Gagliardi, "Diet, nutrition and bone health," Clinica Terapeutica, vol. 156, no. 1-2, pp. 47-56, Article ID 16080661, 2005.

[7] D. E. Kim, S. H. Cho, H. M. Park, and Y. K. Chang, "Relationship between bone mineral density and dietary intake of beta-carotene, vitamin $\mathrm{C}$, zinc and vegetables in postmenopausal Korean women: a cross-sectional study," Journal of International Medical Research, vol. 44, no. 5, pp. 1103-1114, 2016.

[8] M. Nirgude, B. K. Babu, Y. Shambhavi, U. M. Singh, H. D. Upadhyaya, and A. Kumar, "Development and molecular characterization of genic molecular markers for grain protein and calcium content in finger millet (Eleusine coracana (L.) Gaertn.)," Molecular Biology Reports, vol. 41, no. 3, pp. 1189-1200, 2014.

[9] Z. M. Hassan, N. A. Sebola, and M. Mabelebele, "The nutritional use of millet grain for food and feed: a review," Agriculture \& Food Security, vol. 10, no. 1, Article ID 16, 2021.

[10] I. G. N. H. Senevirathne, W. K. S. M. Abeysekera, W. P. K. M. Abeysekera, N. Y. Jayanath, S. P. G. Arachchige, and D. C. M. S. I. Wijewardana, "Antiamylase, antiglucosidase, and antiglycation properties of millets and sorghum from Sri Lanka," Evidence-Based Complementary and Alternative Medicine, vol. 2021, Article ID 5834915, 10 pages, 2021.
[11] A. Kumar, M. Metwal, S. Kaur et al., "Nutraceutical value of finger millet [Eleusine coracana (L.) Gaertn.], and their improvement using omics approaches," Frontiers of Plant Science, vol. 7, Article ID 934, 2016.

[12] M. Rastogi and M. Joshi, "Effect of Ragi (Eleusione coracana) for the development of value added products and their nutritional implication," Asian Journal of Home Science, vol. 10, no. 1, pp. 1-5, 2015.

[13] S. Anitha, D. I. Givens, R. Botha et al., "Calcium from finger millet-a systematic review and meta-analysis on calcium retention, bone resorption, and in vitro bioavailability," Sustainability, vol. 13, no. 16, Article ID 8677, 2021.

[14] M. Correa-Rodríguez, J. C. Rio-Valle, E. González-Jiménez, and B. Rueda-Medina, "The effects of body composition, dietary intake, and physical activity on calcaneus quantitative ultrasound in Spanish young adults," Biological Research For Nursing, vol. 18, no. 4, pp. 439-444, 2016.

[15] P. T. Lawrence, M. P. Grotzke, Y. Rosenblum et al., “The bone health team: a team-based approach to improving osteoporosis care for primary care patients," Journal of Primary Care \& Community Health, vol. 8, no. 3, pp. 135-140, 2017.

[16] A. Elhakeem, J. Heron, J. H. Tobias, and D. A. Lawlor, "Physical activity throughout adolescence and peak hip strength in young adults," JAMA Network Open, vol. 3, no. 8, Article ID e2013463, 2020.

[17] M. B. Pinheiro, J. Oliveira, A. Bauman, N. Fairhall, W. Kwok, and C. Sherrington, "Evidence on physical activity and osteoporosis prevention for people aged 65+ years: a systematic review to inform the WHO guidelines on physical activity and sedentary behaviour," International Journal of Behavioral Nutrition and Physical Activity, vol. 17, Article ID 150, 2020.

[18] M. L. Gourlay and S. A. Brown, "Clinical considerations in premenopausal osteoporosis," Archives of Internal Medicine, vol. 164, no. 6, pp. 603-614, 2004.

[19] M. Correa-Rodríguez, G. Pocovi-Gerardino, J. L. CallejasRubio, R. Ríos-Fernández, B. Rueda-Medina, and N. C. Ortego-Centeno, "Disease damage accrual and low bone mineral density in female patients with systemic lupus erythematosus," Biological Research For Nursing, vol. 23, no. 4, 2021.

[20] S. Ahmad, T. Harris, E. Limb et al., "Evaluation of reliability and validity of the General Practice Physical Activity Questionnaire (GPPAQ) in 60-74 year old primary care patients," BMC Family Practice, vol. 16, no. 1, Article ID 113, 2015.

[21] S. B. El-Sobkey, "Physical activity level and adult Saudi health related quality of life," Open Journal of Therapy and Rehabilitation, vol. 2, pp. 106-113, 2014.

[22] B. D. Pardhe, S. Pathak, A. Bhetwal et al., "Effect of age and estrogen on biochemical markers of bone turnover in postmenopausal women: a population-based study from Nepal," International Journal of Women's Health, vol. 9, pp. 781-788, 2017.

[23] R. Otmar, S. D. Reventlow, M. Morrow, G. C. Nicholson, M. A. Kotowicz, and J. A. Pascol, "A cultural models approach to osteoporosis prevention and treatment," SAGE Open, vol. 2, no. 4, 2012.

[24] A. Bertonazzi, B. Nelson, J. Salvador, and E. Umland, "The smallest available estradiol transdermal patch: a new treatment option for the prevention of postmenopausal osteoporosis," Sage Women's Health, vol. 11, no. 6, pp. 815-824, 2015.

[25] G. de Klerk, J. H. Hegeman, D. van der Velde, J. van der Palen, L. van Bergeijk, and H. J. ten Duis, "The value of laboratory tests in diagnosing secondary osteoporosis at a fracture and 
osteoporosis outpatient clinic," Geriatric Orthopaedic Surgery \& Rehabilitation, vol. 4, no. 2, pp. 53-57, 2013.

[26] A. Cohen, "Premenopausal osteoporosis," Endocrinology and Metabolism Clinics of North America, vol. 46, no. 1, pp. 117-133, 2017.

[27] B. L. Langdahl, "Osteoporosis in premenopausal women," Current Opinion in Rheumatology, vol. 29, no. 4, pp. 410-415, 2017.

[28] A. P. Nanduri, S. Fullman, L. Morell, S. Buyske, and M. L. Wagner, "Pilot study for implementing an osteoporosis education and exercise program in an assisted living facility and senior community," Journal of Applied Gerontology, vol. 37, no. 6, pp. 745-762, 2018.

[29] Y. Dionyssiotis, I. Paspati, G. Trovas, A. Galanos, and G. P. Lyritis, "Association of physical exercise and calcium intake with bone mass measured by quantitative ultrasound," BMC Women's Health, vol. 10, Article ID 12, 2010.

[30] B. Stanghelle, H. Bentzen, L. Giangregorio, A. H. Pripp, and A. Bergland, "Effect of a resistance and balance exercise programme for women with osteoporosis and vertebral fracture: study protocol for a randomized controlled trial," BMC Musculoskeletal Disorders, vol. 19, no. 1, Article ID 100, 2018.

[31] F. D. Saraví and F. Sayegh, "Bone mineral density and body composition of adult premenopausal women with three levels of physical activity," Journal of Osteoporosis, vol. 2013, Article ID 953271, 7 pages, 2013.

[32] C. M. Weaver, W. R. Proulx, and R. Heaney, "Choices for achieving adequate dietary calcium with a vegetarian diet," American Journal of Clinical Nutrition, vol. 70, no. 3, pp. 543S-548S, 1999.

[33] S. Shobana, K. Krishnaswamy, V. Sudha et al., "Finger millet (Ragi, Eleusine coracana L.): a review of its nutritional properties, processing, and plausible health benefits," Advances in Food \& Nutrition Research, vol. 69, pp. 1-39, 2013.

[34] M. Durairaj, G. Gurumurthy, V. Nachimuthu, K. Muniappan, and S. Balasubramanian, "Dehulled small millets: the promising nutricereals for improving the nutrition of children," Maternal and Child Nutrition, vol. 15, no. 3, Article ID e12791, 2019.

[35] M. Divya, S. Karthikeyan, C. Ravi et al., "Isolation of $\beta$-glucan from Eleusine coracana and its antibiofilm, antidiabetic, antioxidant, and biocompatible activities," Microbial Pathogenesis, vol. 140, Article ID 103955, 2020.

[36] P. Verma, N. Shah, and S. Mahajani, "Effect of sodium hydrosulphite treatment on the quality of non-centrifugal sugar: Jaggery," Food Chemistry, vol. 299, Article ID 125043, 2019.

[37] L. A. Marchenkova, A. D. Fesyun, M. Y. Gerasimenko, and E. V. Makarova, "The effect of administration of dietary supplement with calcium and vitamins D 3 and B 6 on calcium homeostasis and falls incidence in patients with high fracture risk undergoing medical rehabilitation," Voprosy Pitaniya, vol. 89, no. 5, pp. 89-100, 2020.

[38] C. Liu, X. Kuang, K. Li, X. Guo, Q. Deng, and D. Li, "Effects of combined calcium and vitamin D supplementation on osteoporosis in postmenopausal women: a systematic review and meta-analysis of randomized controlled trials," Food Function, vol. 11, no. 12, pp. 10817-10827, 2020.

[39] J. P. Raj, S. Venkatachalam, M. Shekoba, J. J. Norris, and R. S. Amaravati, "Dietary calcium intake and physical activity levels among people living in Karnataka, India-An observational hospital-based study," Journal of Family Medicine and Primary Care, vol. 7, no. 6, pp. 1411-1416, 2018. 